\title{
The combined products types of cheese making industry
}

\section{Abstract}

The names of the inventions concerning combined products of cheese branch have been investigated. It is concluded that the most frequent names are processed cheese, soft cheese with ripening and curd.
Volume 5 Issue 3 - 2016

\author{
Musina Olga ${ }^{1,2}$ \\ 'Siberian Research Institute of Cheese-Making, Russia \\ ${ }^{2}$ Institute for Biotechnology, Food and Chemical Engineering at \\ Altai State Technical University, Russia

\begin{abstract}
Correspondence: Olga N Musina, Head of the Scientific Information' Analyses Department, Siberian Research Institute of Cheese-Making (Department of Russian Academy of Sciences), Russia, Tel +73852564612, Email musinaolga@gmail.com
\end{abstract}

Received: November 2I, 2016 | Published: November 25, 2016

\section{Editorial}

A patent search for combined products cheese industry in Russia (1924) conducted $^{1-3}$ and it helped to select 150 of the security documents in accordance with the rules of search. All security documents are classified under International patent classification (IPC). Index patent classification assigned to the document that gives the researcher enough information about the subject of the invention. However, there are some nuances, which is worth a stop especially. We should take into account the fact that patent classification is a formal generalization of the grounds on which the invention classified. To take just one example: if the document will be assigned an index A23C 19/076 "Soft unripened cheese, e.g. cottage cheese or cream cheese", the subject of the invention may be soft cheese and cottage cheese. It is likely that without knowledge of the basics of patent cases, cannot guess to look for the cheese among the special types of cheese. The author would like to see the results of a patent search had a maximum of information not only for specialists who have some knowledge in patenting, but also engineers, practitioner's milk processing for young scientists.

For this you need to perform not only claims relating to combined products, but also their full descriptions. The formula of the invention is the verbal characteristics of the essence of the technical solutions in the form of a set of attributes necessary and sufficient to implement the invention. Is important, in what place of the formula indicates that the product is the combined. This information may be given to first restrictive part of the formula that contains elements in common with the prototype. New features of the invention are contained in the distinctive part of the formula and may relate, for example, the method of salting cheese and be classified accordingly. However, the subject of our search is combined products in the cheese industry, from which it does not follow that the security document is classified on this basis. Therefore, we separately analyzed the description of each security document, selected in accordance with the rules, namely the descriptive section, indicating the technical field to which the invention pertains. During the work drew attention to how the applicants (patentees) are kind of combined product, which is not always clearly reflected in the title of the document.
In the analysis of the documents classified as A23C19/076 (a soft unripened cheese, e.g. cottage cheese or cream cheese), combine the products were distributed in the following way.

"Soft cheese" is defined as a subject of the invention in 18 cases, in two cases, clarified that it was "soft cheese without maturation", in one case, the cheese the characteristic - sweet, spicy, fruity. In patent № 1741717 and the application for the invention № 2004126466 featured homemade cheese.

In 8 cases the subject of the invention is clearly named cottage cheese. Moreover, in three cases clarified the use of the invention:

i. Obtained by the proposed method, the curd is recommended for use in the manufacture of culinary products, curd frozen prepared food, cheese cakes, dumplings, spring rolls, canned food, frozen food (№ 2133095);

ii. Obtained by the proposed method, the curd is recommended for use in the manufacture of cheese, culinary products (№ 2150838);

iii. Invention can be used in the production of cottage cheese products of preventive purpose (№ 2213463).

In 6 cases the object of the invention is a cheese product or a cheese product. Moreover, in the application for the invention № 2004124261 cheese product called quark, and in patent No. 2143205 cheese product described as a product of the General, diet and preventive nutrition for the elderly, with cardiovascular diseases with excess weight, and staying in areas with unfavorable ecological environment.

Often cottage cheese (curd) are called in a more General way “dairy or milk protein product”. In document № 92016058 described milk-protein product such as cheese, and in patent № 1697685 stated that the invention can be used in the production of milk-protein products, cheese products, milk-protein pastes. In the invention № 2245061 described protein fermented milk product, a prototype of which was cheese. Protein dairy products are also devoted to the document № 2032349 and № 2002108466 . The patent for the invention № 2173052 described a method of producing a fermented 
milk product with biological activity, and as an example of such a product given cheese and curd.

Patent № 2197093 has the name "Food product", the study also claims it becomes clear that means a product based on cheese, and the invention applies to products using microorganisms, fruit, vegetables and other organic additives, is a functional food product, can serve as a preventive.

In patent № 2115325 provides a method for producing product having biological activity, and the description of the invention it is specified that this product can be cheese, in which the imperceptible presence of animal tissue.

Also it is significant that the invention "Method of production of cottage cheese low-fat diet with wheat germ flakes” (№ 2210921), where from the name itself it is clear that we are talking about cheese, is assigned an index classification of "production of curd with the addition of non-milk fats and/or non-milk proteins".

In patent № 2242135 relating to the curd mass, none of the indices of the IPC does not concern directly a soft immature cheese (A23C19/02 - producing the curd, A23C19/082 - the introduction of substances in the cheese mass before and/or during melting; saltshot filling monoblocs, A23C23/00 other dairy products). Author's certificate № 181978 "Method of producing milk protein products" in the description contains the clarification - so the milk-protein product can be like curd, which is used for preparation of various milk protein products - cream, sour milk, however, the classification of Dana - A23C19/093 (introduction of non-milk fats and/or non-milk proteins). Document № 1785421 explains that protein mass, obtained as described in this method can be used to produce other products (cheeses curd mass).

In three documents (№№ 1804301, 2240698, 2001135059) the object of the invention is a soft cheese, but also there is no classification A23C 19/076, and inventions classified as "special types of cheese; cheese, cheese products, manufacture of cheese and products from it”. In patent № 2229811 nor the title of the invention "Method of production of cheese "Spring"" nor his classification (A23C19/068 - special types of cheese A23C19/02 - the production of the cheese mass) does not make it clear what specific kind of cheese it is, and only a careful reading of the description makes clear cheese without ripening.

In patents №№ 2100935, 2101968 and 2178645 they are talking about some "dairy products" (the latter clarified that the invention relates to the production of food products enriched with micronutrients); however, in classification there is a subgroup A23C19/076.

In 59cases the subject of the invention was processed cheese (composition or method of receipt). In a number of documents specify the characteristics and purpose of cheese:

i. Sweet cream cheese (patents №№ 2225124, 2229812, 2229813, 2229814, 2229815, 2229816);

ii. Low-fat processed cheese (author’s certificate № 1746988);

iii. Filled processed cheese, cheese can be consumed for medicinal purposes in the treatment of gastritis with low acidity, and liver disease, kidney disease, and also for sauces or as a seasoning for meat, fish and pasta, improving their digestibility (patent № 1746989);

iv. Processed cheese can be consumed directly as food or for soups, as seasoning for fish, meat or pasta (author's certificate № 1306550);

v. The product is used for children and patients with gastritis, colitis, cholecystitis, chronic diseases of liver and pancreas (author’s certificate № 929040);

vi. Processed cheese can be consumed directly as food or for soups and as a seasoning for meat, fish and pasta (patent № 2010531);

vii. Processed cheese can be used for direct consumption and also as seasoning for various dishes (patent № 2225125);

viii. Processed cheese can be consumed directly as food or used as a seasoning for meat, fish and pasta (patent № 2266011).

ix. In other cases, the object of the invention is described somewhat vaguely, and to understand that they are talking about processed cheese conveniently with the help of their IPC:

x. Cream cheese (patent № 2200419, IPC A23C19/08 - processed cheeses; processed cheese, e.g. melting, emulsifying, sterilization, A23C19/082 - the introduction of substances in the cheese mass before and/or during melting; salts-hot filling monoblocs, A23C19/084 - cheese processing and/or introduction of various substances after melting);

xi. Processed mass, enriched with preventive additives (patent № 2173054, A23C19/08 - processed cheeses; processed cheese, e.g. melting, emulsifying, sterilization);

xii. Cheese pasta (patent № 2212810, A23C23/00 other dairy products, A23C19/08 - processed cheeses; processed cheese, e.g. melting, emulsifying, sterilization);

xiii. Processed cheese product (application for invention № 2002134953, A23C23/00 other dairy products, A23C19/08 processed cheeses; processed cheese, e.g. melting, emulsifying, sterilization, A23C19/076 - soft unripened cheese, e.g. cottage cheese or cream cheese).

Patent documents in the subgroup A23C19/086 (cheese powder; products from dry cheese) basically exhaustively described in the classification, the name and description of the document. For example, author's certificate № 1138099 "Method of obtaining dry cheeselike product with mushroom flavor" in the description is explained as "cheese-like product, used as seasonings, sauces and filler in the manufacture of processed cheese (light yellow powder with strong cheese and mushroom taste and smell)”; patent № 2122328 describes the dry mixture for pasta cheese (cheese analogue), № 2141213 dry cheese; № 2198528 - a mix of dairy and plant-based dry milk powder, which can be used as the basis or a component for industrial production of dairy products of different consistencies (i.e. pasta). At the same time, a number of inventions, describes a dry cheese, do not have classification A23C 19/086. This author’s certificate № 698602 protecting the method of producing a dry cheese; author's certificate № 936867, describes how the national cheese, including dry and patent № 2086141 devoted to the method of producing a dry cheese-like product (dry protein product based on natural cheese and vegetable protein). 
The 23 patent documents as the object of the invention called cheese, meaning cheese, and in the obtaining process there is a stage of maturation. In a number of patent documents stated:

i. Cheese (patent № 2169475);

ii. Roquefort type cheese (patent № 2164754);

iii. Rennet hard cheese (№№ 2265342, 2231959, 2231958, 2141211, 1205870);

iv. Pickled cheese (№ 938897, 1274667, 1281241);

v. Hard cheese with low temperature of second heating (№№ $2173053,2175841,2155490)$.

Among the array of combined products relating to cheese undergoing maturation stage, the most common classification of security documents according to the index A23C19/068 (15 times) - special types of cheeses, as well as A23C19/00 (cheese, products cheese, manufacture of cheese and products from him) -9 and A23C19/02 (production of cheese mass)-8.

In the study of inventive activity for the protection of the combined maturing of the cheese occurs two periods: the first from 1974 to 1987 - when he patented 1-2 such inventions; and second, from 1998 to 2003 when the annual number of documents obtained increases from 1-2 to $4-6$.

In addition, among the combined products of the cheese-making industry under the requirements of the search rules we find the following products not mentioned above:

i. High-protein paste product rennet cheese type for baby food (author's certificate № 1316630); ii. Seasoning cheese (author’s certificate № 1124910);

iii. Cheese mass for melting (author’s certificate № 786962);

iv. Protein mass (patent № 2144293);

v. Smoked cheese product (patent № 2197828);

vi. Cheese rolls (application for invention № 2000130655).

Thus, among the entire array of patent documents on combined products of cheese making industry, most often as a specific type of this product called processed cheese, cheese (passing the stage of maturation), soft cheese and curd (curd products, cottage cheese products, curds).

\section{Acknowledgements}

None.

\section{Conflict of interest}

Author declares that there is no conflict of interest.

\section{Referencers}

1. Musina ON, Shhetinin MP, Sahrynin MN. Condition and tendencies of development of biotechnology combined dairy products. Izd-vo AltSTU. 2006; ISBN:5756806067.

2. Musina ON. Combined products in the Russian cheese making. Izd-vo Alt. un-ta. 2007; ISBN:5790406785.

3. Musina ON, Shhetinin MP. Multicomponent products based on a combination of dairy and grain materials. Izd-vo Alt un-ta. 2010; ISBN:5790410286. 